\title{
Optimalisasi Pelayanan Prima dalam Meningkatkan Potensi Bisnis Usaha Mikro Kecil dan Menengah (UMKM) di Cilember, Bogor
}

\author{
Iis Mariam ${ }^{1}$, Nidia Sofa ${ }^{2}$, Nining Latianingsih ${ }^{3}$, Azwar $^{4}$ \\ 1,2,3.4 Lecturer, Business Administration Department, State Polytechnic of Jakarta \\ Jl. Prof.Siwabessy, Kampus Baru UI, Depok 16424 \\ iis.mariam@yahoo.com,nidia_sofa@yahoo.com,nilaahen@yahoo.co.id, \\ azwar@bisnis.pnj.ac.id
}

\begin{abstract}
Abstrak
Dalam era teknologi informasi saat ini kecepatan dalam memberikan pelayanan bisnis kepada konsumen berdampak pada persaingan bisnis tidak terkecuali pada pelaku usaha mikro dan kecil menengah (UMKM) yang ada di Bogor, Jawa Barat. Salah satu kegiatan yang dilakukan dalam pengabdian pada masyarakat yang berada di desa Cilember, Cisarua, Bogor-Jawa Barat adalah membentuk koperasi yang berbadan hukum dan dapat menampung kebutuhan pelaku usaha berbisnis serta mempermudah mempertemukan pelaku usaha dengan supplier ataupun pembeli yang tertarik dengan produk yang dijual. Pelaku UMKM di desa Cilember memiliki usaha yang beragam, seperti: pengusaha bunga kayu, pengrajin boneka, penjual makanan dan minuman, pengelola Eco-Village. Tujuan pengabdian pada masyarakat ini adalah: (1) mengindentifikasi bentuk pelatihan pelayanan prima kepada pengurus koperasi dan pengrajin yang tergabung dalam UMKM, (2) strategi yang dilakukan pelaku usaha bunga kayu dalam memasarkan produknya. Metode yang digunakan adalah deskriptif kualitatif, teknik pengumpulan data observasi, dan wawancara. Pelaku usaha yang tergabung di koperasi bunga kayu mekar Cilember ada 300 orang dengan jenis usaha yang beragam. Hasilnya menunjukkan bahwa pelayanan yang diberikan kepada konsumen yang memesan dan membeli kerajinan bunga kayu sudah dilakukan menggunakan komunikasi yang mudah dimengerti dan memberikan rasa puas kepada konsumen. Strategi yang dilakukan dalam memasarkan produknya adalah mengikuti pameran yang diadakan pemerintah daerah Bogor, ikut dalam kegiatan bazar, kemasyarakatan dan berjualan di tempat wisata serta penjualan berbasis on-line.
\end{abstract}

Kata kunci: pelayanan, UMKM, koperasi, bunga kayu

\begin{abstract}
In the era of information technology, the speed of providing business services to consumers has an impact on business competition, including micro and small and medium enterprises (SMEs) in Bogor - West Java. The growth of micro and small and medium enterprises (SMEs) today must be able to answer the needs of consumers or the community so that they are able to winning a business. One of the activities carried out by SMEs located in the village of Cilember, Cisarua, Bogor-Jawa Barat and became as a member of cooperative that can accommodate the needs of people running business and have good networking with the suppliers or buyers who are interested in the products. SME's actors in Cilember village have diverse businesses, such as: wood flower entrepreneurs, doll craftsmen, food and beverage sellers, tourism of EcoVillage. The research objectives in community service are: (1) to identify coaching is needed regarding excellent service for cooperative and customers, (2) strategies are carried out by flowers business actors in marketing their products when connected with the concept of service to consumers. The research method used qualitative research, observation data collection techniques, and interviews. There are 300 business people who are members of the wood flower cooperative in Cilember village with various types of businesses. The results research is that the services provided to consumers who order and buy wood flower crafts have been done using easy-to-understand communication and give satisfaction to consumers. The strategy carried out in marketing its products is to participate in exhibitions held by the Bogor regional government, participate in community activities, sell at tourist attractions and selling product with on-line.
\end{abstract}

Keywords: services, SMEs, cooperatives, wood flowers

\section{PENDAHULUAN}

Dalam era globalisasi saat ini dan perkembangan teknologi informasi yang demikian cepat, maka perubahan tatanan pada masyarakatpun menjadi semakin cepat. Jumlah usaha mikro kecil dan menengah (UMKM) di Indonesia terus meningkat seperti yang ada di daerah kabupaten Bogor. Salah satu daerah yang berdekatan dengan tempat wisata di Ciawi Bogor yaitu desa Cilember. Cilember memiliki potensi wisata tidak hanya potensi alam yang indah yang tekenal dengan nama Curug ....., adanya eco wisata untuk wisatawan yang datang tidak hanya domestik tetapi juga asing. Potensi wisata yang menarik dapat menjadi salah satu 
daya tarik wisatawan untuk berkunjung dan dampaknya usaha kecil dan menengah (UMKM) yang berada di Cilember juga meningkat.

\section{METODE PENELITIAN}

Metode yang digunakan dalam membahas masalah ini adalah deskriptif kualitatif dengan teknik pengumpulan data melalui: wawancara dan observasi dengan ketua koperasi Kayu Cilember Mekar desa Cilember, Bogor dan pedagang bunga kayu yang tergabung dalam koperasi Bunga Kayu Cilember Mekar.

\section{HASIL DAN PEMBAHASAN}

Pembahasan hasil pengabdian disajikan dalam bentuk uraian deskriptif. Hasil wawancara dengan Samin (Ketua Koperasi Bunga Kayu Cilember Mekar mengenai potensi usaha bunga kayu adalah "...potensi usaha bunga kayu telah banyak memberikan kontribusi penghasilan dan berdampak pada pemberdayaan ekonomi masyarakat di Cilember. Tingkat penjualan bunga kayu terus meningkat dari tahun ke tahun melalui kegiatan yang diselenggarakan pemerintah, bazar atau penjualan di tempat wisata di daerah Bogor. Para pengrajin bunga kayu di Cilember merupakan usaha yang sudah lama berjalan, akan tetapi masih ditemukan kendala seperti pasokan bahan baku, pola pencatatan keuangan serta koperasi berbadan hokum. Tahun 2018 kami mendapatkan bantuan dari PNJ dalam pengurusan pengajuan koperasi berbadan hukum sehingga diharapkan koperasi ini dapat memberdayakan perekonomian anggota dan masyarakat di Celember".

Pengrajin usaha bunga kayu yang tergabung dalam koperasi Bunga Kayu Cilember Mekar di Celember, Bogor ada 300 orang dan memiliki usaha tidak hanya bunga kayu saja akan tetapi juga ada makanan dan minuman yang berjualan di taman wisata Matahari, Dalam menjalankan usahanya pengrajin bunga kayu selama ini untuk membeli bahan baku dilakukan sendiri sehingga harga menjadi lebih mahal. Oleh karena itu dengan adanya koperasi Bunga Kayu Cilember Mekar diharapkan beberapa masalah yang selama ini terjadi dapat diatasi, yaitu: (1) penyediaan dan pembelian bahan baku dapat dilakukan melalui koperasi sehingga harga menjadi lebih murah, (2) pemasaran produk bunga kayu dapat dibantu dengan sering mengikuti pameran yang diselenggarakan pemda Bogor dan bazar di masyarakat, (3) memberikan bantuan penjualan berbasis on-line walaupun masih terbatas jumlahnya, (4) memberikan pendampingan dalam pencatatan pembukuan, dan (5) memberikan informasi pelatihan dalam memberikan pelayanan yang prima kepada pembeli dan supplier bahan.

Upaya lainnya yang dilakukan koperasi untuk membantu penjual makanan dan miniuman yang berjualan di Taman Wisata Matahari, Bogor adalah dengan: (1) memberikan pendampingan cara menjual yang baik, dan (2) memberikan cara pelayanan yang prima kepada pembeli sehingga diharapkan omzet penjualan makanan dan minuman meningkat.

Materi yang diberikan dalam pencatatan pembukuan sederhana pada koperasi Bunga Kayu Cilember Mekar dijelaskan proses pencatatan harian untuk barang yang masuk (stok di gudang penyimpanan) dengan barang yang terjual. Proses pencatatan barang dapat diakses oleh semua pengurus koperasi sehingga transparan.

Gambar 1 Pelatihan Pencatatan

Pembukuan Sederhana

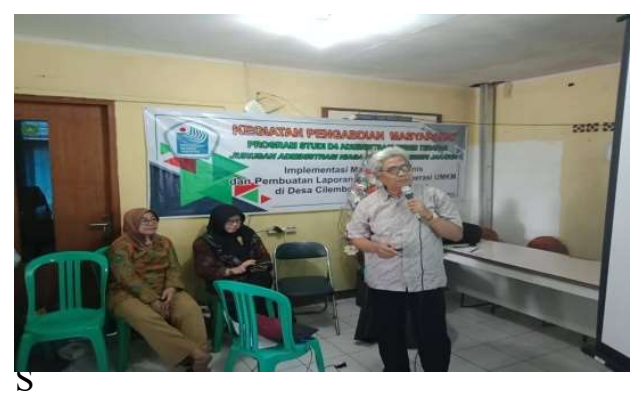

Sumber: data diolah, 2018

Materi yang diberikan untuk pelatihan dalam pengabdian pada masyarakat ini pada sesi pertama adalah mengenai laporan keuangan untuk koperasi dan UKM. Kendala dan permasalahan yang sering dikeluhkan untuk koperasi dan UKM adalah: (1) tidak memiliki laporan keuangan, (2) sulitnya akses ke lembaga keuangan formal seperti bank, (3) perhitungan harga pokok yang tidak akurat, dan (4) pengendalian terhadap penggunaan laba untuk prive. Manfaat yang dapat diperoleh pengusaha bunga kayu di Cilember dalam mengetahui cara pembuatan laporan keuangan adalah: (1) sebagai alat pertanggungjawaban dan alat penilaian kinerja koperasi, (2) posisi keuangan setiap saat dapat diketahui, (3) selama periode usaha maka laba rugi dapat dimonitor, dan (4) informasi yang diberikan kepada pihak luar koperasi dan UKM dapat disampaikan dengan benar. Peserta pada akhir pelatihan laporan keuangan dan proses pembukuan meliputi: buku kas, kartu utang, kartu piutang, kartu persediaan, ikhtisar laba/rugi, perubahan modal serta pembuatan neraca.

Untuk materi pelayanan, maka kepada pengrajin bunga kayu dan penjual makanan minuman dilakukan komunikasi lisan secara dua arah menggunakan bahasa Indonesia yang dapat diterima dengan baik sesuai budaya setempat. Pelayanan yang diberikan merujuk pada pelayanan kepada pembeli dan pelanggan sehingga merasa puas. Adapun materi yang diberikan dalam sesi kedua ini adalah: (1) pengertian pelayanan, (2) konsep pelayanan kepada pelanggan, (3) pengertian komunikasi tertulis dan lisan, (4) hambatan komunikasi, serta 
(5) media komunikasi yang digunakan dalam meningkatkan loyalitas pelanggan untuk membeli produk pengrajin dan penjual. Hasilnya adalah pengrajin dan pengusaha selalu mematuhi prinsip 4S yaitu: senyum, sapa, salam dan santun dan hal ini merupakan tindakan yang selama ini sudah pengrajin dan penjual baik anggota koperasi dan penjual di desa Cilember lakukan.

Gambar 2 Pembicara dan Pengurus

Koperasi Bunga Kayu Cilember Mekar

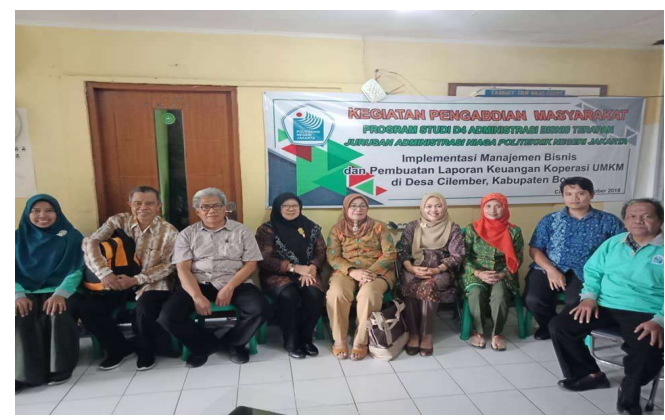

Sumber: data diolah, 2018

Dalam pengabdian ini diserahkan seperangkat bantuan berupa ATK dan Peralatan kantor untuk membantu administrasi koperasi serta akta notasi untuk koperasi.

Gambar 3 Papan Nama Koperasi

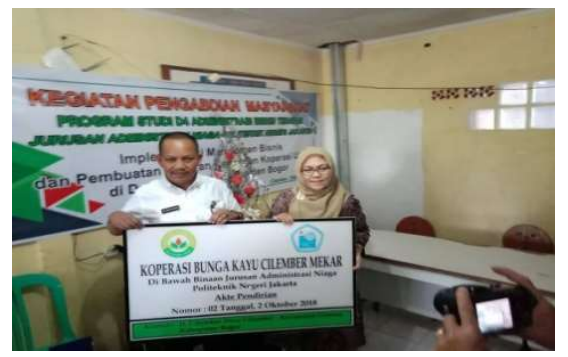

Sumber: data diolah, 2018

Gambar 4 Penyerahan Akta Notaris

Koperasi Bunga Kayu Cilember Mekar

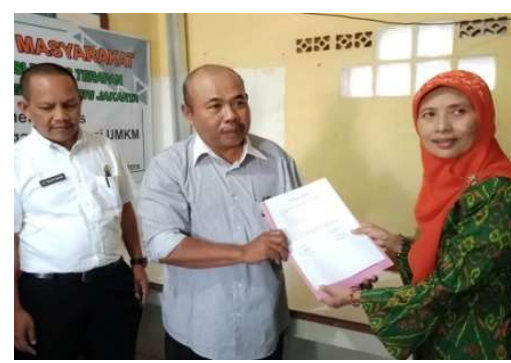

Sumber:data diolah, 2018

Gambar 5 Logo

Koperasi Bunga Kayu Cilember Mekar

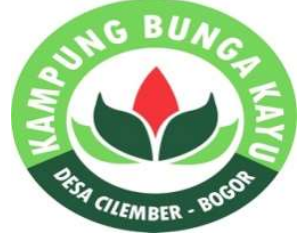

Sumber: data diolah, 2018
Dari kegiatan yang dilakukan dapat dijelaskan bahwa strategi pelayanan prima yang dilakukan untuk anggota koperasi Bunga Kayu Cilember Mekar, Bogor melalui analisis SWOT dapat dilihat pada tabel berikut:

Tabel 1. Analisis SWOT strategi pelayanan prima

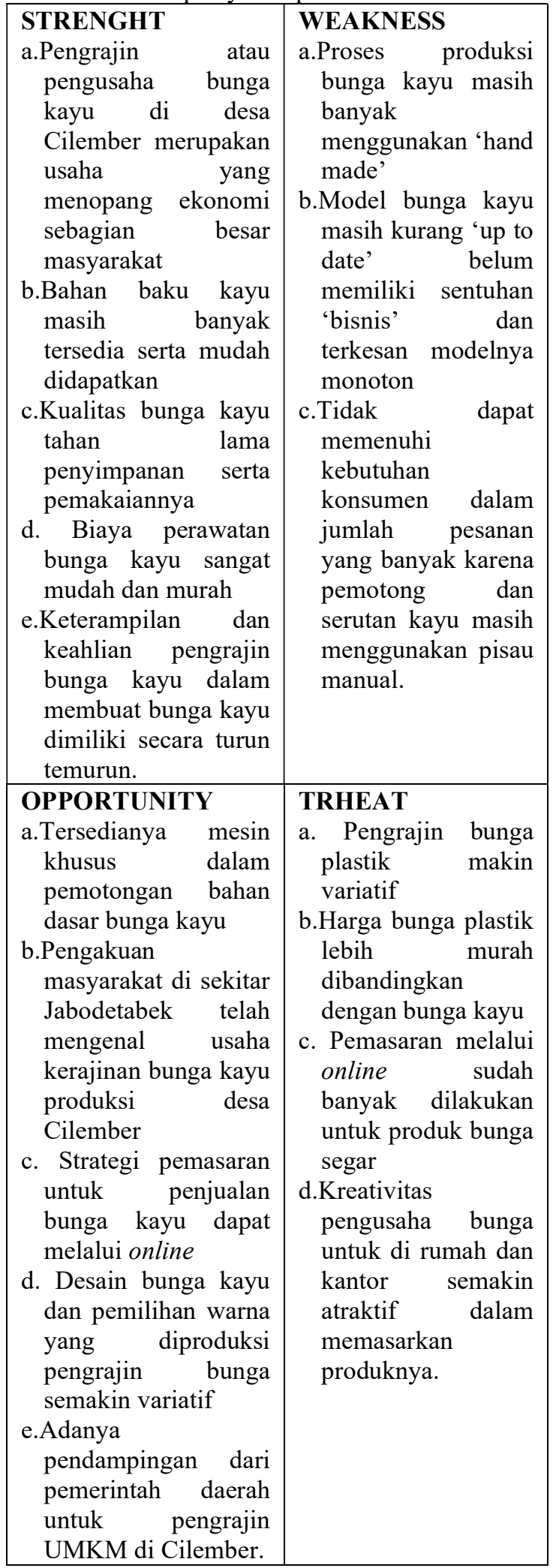

Sumber: data diolah, 2018 


\section{SIMPULAN DAN SARAN}

A. Simpulan:

1. Pelayanan prima menjadi salah satu faktor penting dalam meningkatkan potensi bisnis Bunga Kayu di desa Cilember;

2. Potensi pengrajin bunga kayu sudah dilakukan secara turun temurun dan dikerjakan di rumah tangga masing-masing;

3. Koperasi Bunga Kayu Cilember Mekar di desa Cilember, Bogor yang baru terbentuk tahun 2018 menjadi wadah formal untuk membantu memberdayakan para pengrajin dalam melakukan bisnis.

\section{B. Saran}

1. Perlu diberikan pelatihan dan pendampingan kepada pegusaha UMKM bunga kayu dalam membuat model bunga kayu lebih kreatif

2. Pemasaran bunga kayu perlu diperluas kembali tidak hanya di Jabodetabek tetapi juga daerah lainnya

3. Bentuk pemasaran online perlu diberikan kepada pengusaha atau pengrajin bunga kayu agar dapat menerima tawaran konsumen lebih luas lagi

\section{UCAPAN TERIMA KASIH}

Penulis mengucapkan terima kasih kepada: (1) Politeknik Negeri Jakarta yang telah mendanai kegiatan pengabdian pada masyarakat, dan (2) Kepala Desa Cilember-Bogor yang telah bekerjasama dalam memberikan informasi data dan dukungan terhadap pelaksanaan keberhasilan pengabdian ini.

\section{DAFTAR PUSTAKA}

[1] Barata, Ateb Adya. 2003. Dasar-dasar pelayanan prima, jakarta: PT Elek Mediakomputindo

[2] Fandy, Tjiptono dan Gregorius Chandra. 2007. Service, Quality Statisfaction, Yogyakarta: Andi Offset

[3] Rahmayanti, Nina. 2013. Manajemen Pelayanan Prima, Yogyakarta: Graha Ilmu

[4] Rangkuti, Freddy. 2002. Measuring Customer Statisfaction: PT Gramedia Pustaka Utama, Jakarta

[5] Etzkowitz, Henry \& Leydesdorff, L. (2000). The dynamic of innovation: From national systems and 'mode 2' to a triple helix of university -industry-government relations. Research Policy, 29 (2), 109-123

DOKUMEN DAN PERATURAN

[1] UU Nomor 20 Tahun 2008 mengenai UMKM 